\title{
Enhancement of specific T-lymphocyte responses by monocyte-derived dendritic cells pulsed with E2 protein of human papillomavirus 16 and human p16INK4A
}

\author{
Nuchsupha Sunthamala ${ }^{1,2}$, Neeranuch Sankla ${ }^{1}$, Jureeporn Chuerduangphui ${ }^{2,3}$, Piyawut Swangphon ${ }^{2,4}$, \\ Wanchareeporn Boontun ${ }^{1}$, Supakpong Ngaochaiyaphum ${ }^{1}$, Weerayut Wongjampa ${ }^{2,5}$, Tipaya Ekalaksananan ${ }^{2,5}$, \\ Chamsai Pientong ${ }^{\text {Corresp. 2, } 5}$ \\ 1 Department of Biology, Faculty of Science, Mahasarakham University, Maha Sarakham, Thailand \\ 2 HPV \& EBV and Carcinogenesis Research Group, Khon Kaen University, Khon Kaen, Thailand \\ 3 Department of Microbiology, Faculty of Science, Kasetsart University, Bangkok, Thailand \\ 4 Faculty of Medical Technology, Prince of Songkla University, Hat Yai, Songkla, Thailand \\ 5 Department of Microbiology, Faculty of Medicine, Khon Kaen University, Khon Kaen, Thailand \\ Corresponding Author: Chamsai Pientong \\ Email address: chapie@kku.ac.th
}

Introduction: Prophylactic vaccines are already available for prevention of human papillomavirus (HPV) infection. However, we still await development of therapeutic vaccines with high efficiency for stimulating specific T lymphocytes to clear HPV infection.

Objective: This study investigates the potential for subunits of human p16INK4a protein and E2 protein of HPV16 to stimulate dendritic cells and enhance the specific response of T lymphocytes against HPVinfected cells.

Methodology: Immunogenic epitopes of HPV16 E2 and p16INK4a proteins were predicted through the common HLA class I and II alleles present in the Thai population. Then, monocyte-derived dendritic cells (MDCs) were pulsed with HPV16 E2 and/or p16INK4a protein s and their maturity assessed. MDCs pulsed with either or both of these proteins at optimal concentrations were used for activation of autologous $T$ lymphocytes and IFN-Y production was measured for specific response function.

Results: HPV16 E2 and p16INK4a proteins contain various immunogenic epitopes which can be presented by antigen-presenting cells via both HLA class I and II molecules. The stimulation of MDCs with either HPV16 E2 or p16INK4a proteins increased percentages and mean fluorescence intensity (MFI) of $\mathrm{CD}_{83}{ }^{+} \mathrm{MDCs}$ in a dose-dependent manner. An optimum concentration of $250 \mathrm{ng} / \mathrm{mL}$ and $150 \mathrm{ng} / \mathrm{mL}$ of HPV16 E2 and p16INK4a proteins, respectively, stimulated MDCs via the MAPK pathway (confirmed by use of MAPK inhibitors). T lymphocytes could be activated by MDCs pulsed with these proteins, leading to high percentages of both $\mathrm{CD} 4^{+}$IFN- $\gamma^{+} \mathrm{T}$ lymphocytes and $\mathrm{CD} 8^{+}$IFN $-\gamma^{+} \mathrm{T}$ lymphocytes. The production of IFN- $\gamma$ was higher in co-cultures containing MDCs pulsed with HPV16 E2 protein than those pulsed with p16INK4a. Interestingly, MDCs pulsed with a combination of HPV16 E2 and p16INK4a significantly

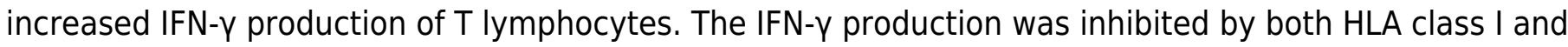
II blockade, particularly in co-cultures with MDCs pulsed with a combination of HPV16 E2 and p16INK4a.

Conclusions: This suggests that MDCs pulsed with both proteins enhances specific response of both $\mathrm{CD}^{+}$and $\mathrm{CD}^{+} \mathrm{T}$ lymphocytes. This study might provide a strategy for further in vivo study of stimulation of T lymphocytes for therapy of HPV-associated cancer. 


\section{Enhancement of specific T-lymphocyte responses by}

\section{2 monocyte-derived dendritic cells pulsed with E2 protein of}

\section{3 human papillomavirus 16 and human p16INK4A}

4 Nuchsupha Sunthamala ${ }^{1,2}$, Neeranuch Sankla ${ }^{1}$, Jureeporn Chuerduangphui ${ }^{2,3}$, Piyawut

5 Swangphon ${ }^{2,4}$, Wanchareeporn Boontun ${ }^{1}$, Supakpong Ngaochaiyaphum ${ }^{1}$, Weerayut

6 Wongjampa ${ }^{2,5}$, Tipaya Ekalaksananan ${ }^{2,5}$, Chamsai Pientong $2,5^{*}$

$8{ }^{1}$ Department of Biology, Faculty of Science, Mahasarakham University, Mahasarakham,

9 Thailand

$10{ }^{2} \mathrm{HPV} \& \mathrm{EBV}$ and Carcinogenesis Research Group, Khon Kaen University, Khon Kaen,

11 Thailand

$12{ }^{3}$ Department of Microbiology, Faculty of Science, Kasetsart University, Bangkok, Thailand

$13{ }^{4}$ Faculty of Medical Technology, Prince of Songkla University Hat Yai, Songkla, Thailand

$14{ }^{5}$ Department of Microbiology, Faculty of Medicine, Khon Kaen University, Khon Kaen,

15 Thailand

17 Corresponding Author:

18 Chamsai Pientong

19 Department of Microbiology, Faculty of Medicine, Khon Kaen University, Khon Kaen, 44150,

20 Thailand

21 * Email address: chapie@kku.ac.th (CP) 


\section{Abstract}

23 Introduction: Prophylactic vaccines are already available for prevention of human

24 papillomavirus (HPV) infection. However, we still await development of therapeutic vaccines

25 with high efficiency for stimulating specific T lymphocytes to clear HPV infection. Objective:

26 This study investigates the potential for subunits of human p16INK4a protein and E2 protein of

27 HPV16 to stimulate dendritic cells and enhance the specific response of T lymphocytes against

28 HPV-infected cells.

29 Methodology: Immunogenic epitopes of HPV16 E2 and p16INK4a proteins were predicted

30 through the common HLA class I and II alleles present in the Thai population. Then, monocyte-

31 derived dendritic cells (MDCs) were pulsed with HPV16 E2 and/or p16INK4a proteins and their

32 maturity assessed. MDCs pulsed with either or both of these proteins at optimal concentrations

33 were used for activation of autologous T lymphocytes and IFN- $\gamma$ production was measured for

34 specific response function.

35 Results: HPV16 E2 and p16INK4a proteins contain various immunogenic epitopes which can be

36 presented by antigen-presenting cells via both HLA class I and II molecules. The stimulation of

37 MDCs with either HPV16 E2 or p16INK4a proteins increased percentages and mean

38 fluorescence intensity (MFI) of $\mathrm{CD} 83^{+} \mathrm{MDCs}$ in a dose-dependent manner. An optimum

39 concentration of $250 \mathrm{ng} / \mathrm{mL}$ and $150 \mathrm{ng} / \mathrm{mL}$ of HPV16 E2 and p16INK4a proteins, respectively,

40 stimulated MDCs via the MAPK pathway (confirmed by use of MAPK inhibitors). T

41 lymphocytes could be activated by MDCs pulsed with these proteins, leading to high percentages

42 of both $\mathrm{CD} 4^{+}$IFN- $\gamma^{+}$T lymphocytes and CD8 ${ }^{+}$IFN- $\gamma^{+}$T lymphocytes. The production of IFN- $\gamma$

43 was higher in co-cultures containing MDCs pulsed with HPV16 E2 protein than those pulsed

44 with p16INK4a. Interestingly, MDCs pulsed with a combination of HPV16 E2 and p16INK4a 
45 significantly increased IFN- $\gamma$ production of T lymphocytes. The IFN- $\gamma$ production was inhibited

46 by both HLA class I and II blockade, particularly in co-cultures with MDCs pulsed with a

47 combination of HPV16 E2 and p16INK4a.

48 Conclusions: This suggests that MDCs pulsed with both proteins enhances specific response of

49 both $\mathrm{CD}^{+}$and $\mathrm{CD} 8^{+} \mathrm{T}$ lymphocytes. This study might provide a strategy for further in vivo

50 study of stimulation of T lymphocytes for therapy of HPV-associated cancer.

51

52 Keywords: human papillomavirus (HPV), HPV16 E2, p16INK4a, dendritic cells, T lymphocytes 

incidence and is a common cause of deaths in low- and middle-income countries. There are around 527,624 new cases of cervical cancer annually worldwide and 265,672 deaths. Early sexual behavior and an increase in HPV infections has led to increasing incidence of cervical cancer in younger women [1]. HPV infection causes genetic and epigenetic changes that can promote cancer development. This virus is associated with over $90 \%$ of cervical cancer cases [2]. Currently, only a prophylactic vaccine is available for HPV infection: no effective therapeutic vaccine has been developed $[3,4]$. Immunotherapy is a strategy to promote the therapeutic efficiency for HPV infection. Stimulating T lymphocytes and inducing differentiation of non-protective $\mathrm{CD}^{+} \mathrm{T}$ lymphocytes to cytotoxic $\mathrm{T}$ lymphocytes (CTLs) can destroy HPVinfected cells and cancer cells. In addition, long-term $\mathrm{CD}^{+} \mathrm{T}$ cells can recognize antigens and can release cytotoxic molecules $[5,6]$. Several mechanisms have been used to stimulate $\mathrm{T}$ lymphocytes for vaccine development. One is stimulation by activated dendritic cells (DCs) [5]. Dendritic cells are antigen presenting cells (APCs) which present antigens to T lymphocytes association with molecules of the major histocompatibility complex (MHC) class I and II. Dendritic cells can stimulate both $\mathrm{CD}^{+} \mathrm{T}$ lymphocytes and $\mathrm{CD}^{+} \mathrm{T}$ lymphocytes [7]. Therefore, the dendritic cells might be designed as the dendritic-based vaccine for HPV infection. HPV and high-risk HPV. HPV16, a high-risk HPV, is highly associated with various cancers [8]. Some proteins of HPV are immunogenic such as E2, E6, and E7. These are all "early" proteins, expressed in an early stage of infection. The HPV E6 and E7 proteins are oncogenic, often referred to as oncoproteins. These early proteins can stimulate the adaptive immune response, but HPV can evade the immune system by modulating immune responses [9-11]. Thus, the 
90 innate immune cells that play initial roles in stimulating the adaptive immune response are

91 important to study. HPV infection also results in over-expression of p16INK4a via the activity of

92 the HPV E7 oncoprotein [12]. The immune response to host p16INK4a and HPV E2 is induced

93 via specific $\mathrm{CD}^{+}$cytotoxic $\mathrm{T}$ lymphocytes and antibody responses to virus antigens and

94 abnormal cells $[13,14]$. Therefore, pulsing of dendritic cells with a combination of p16INK4a

95 and HPV16 E2 proteins might be a promising strategy for enhancing specific T-lymphocyte

96 responses against HPV infection.

97 Here, we aimed to develop human p16INK4a and HPV16 E2 proteins for stimulation of

98 dendritic cells, a link to the adaptive immune response, which enhances T-lymphocyte responses

99 against HPV-infected cells. The HPV16 E2 and p16INK4a proteins were expressed using a

100 bacterial system. The purified proteins were pulsed to immature monocyte-derived dendritic cells

101 (MDCs) and presented as antigens to autologous T lymphocytes. The efficiency of the HPV16

102 E2 and p16INK4a proteins was evaluated in vitro by examining their capacity to induce

103 immature MDCs to develop into mature MDCs and to enhance numbers of IFN- $\gamma$-producing

$104 \mathrm{CD}^{+}$and $\mathrm{CD}^{+} \mathrm{T}$ lymphocytes. The role of mitogen-activated protein kinase (MAPK) on

105 activation of MDCs was determined. Specific HLA blockades were used to confirm the type of

106 T-lymphocyte responses. This research reveals important information for development of

107 protein-based subunit vaccines for therapy of HPV-associated cancer.

108 Materials and methods 
112 shock into competent Escherichia coli BL21 cells and the resulting cells were used for protein

113 expression[15, 16]. The bacteria were cultivated for 24 hours in Luria-Bertani (LB) broth

114 containing $100 \mu \mathrm{g} / \mathrm{ul}$ of ampicillin at $37^{\circ} \mathrm{C}$. Expression of p16INK4a and HPV16 E2 proteins

115 was induced by adding isopropyl thiogalactoside (IPTG) (Thermo Scientific, MA, US). Proteins

116 were extracted using B-PERR Bacteria Protein Extraction Reagent (Thermo Scientific, MA, US).

117 The desired proteins were purified by using HisPur Cobalt Purification Kit (Thermo Scientific,

118 MA, US) and removed the endotoxin by using Pierce High Capacity Endotoxin Removal Resin

119 (Thermo Scientific, MA, US). Protein concentration was measured using Bradford's method

120 [17]. The identities of the purified proteins were confirmed by SDS-PAGE and western blot

121 analysis using anti-histidine antibody, anti-HPV16 E2 antibody, and anti-p16INK4A antibody

$122[18]$.

123 Immunogenic epitope prediction of HPV16 E2 and p16INK4a

124 proteins for HLA class I and II binding

125 The common HLA class I and II molecules in the Thai population were identified at

126 http://www.allelefrequencies.net/. Possible binding epitopes of HLA class I and II for HPV16 E2

127 and p16INK4a proteins were predicted using two databases, SYFPEITHI and NetMHCpan

128 version $4.0[19,20]$. The prediction was performed using 9-meric amino-acid residues for HLA

129 class I and 15-meric amino-acid residues for HLA class II epitopes, respectively.

130 Isolation of $\mathrm{CD14}^{+}$peripheral blood mononuclear cell (PBMC) and

131 cultivation of monocyte-derived dendritic cells (MDCs) 
133 The study was approved by the Human Ethics Research Committee of Khon Kaen University

134 (No. HE611307). The PBMC were separated by centrifugation with Lymphoprep (Stemcell

135 technologies, Oslo, Norway) [21]. CD14 ${ }^{+}$monocytes were isolated from PBMC with CD14

136 magnetic particles to which an anti-human CD14 monoclonal antibody was conjugated and using

137 the IMag separator (BD Biosciences, CA, USA). The $95 \%$ purity of CD $14^{+}$monocytes was

138 confirmed using flow cytometry. The $\mathrm{CD} 14^{+}$monocytes of each volunteer were separately

139 cultured in RPMI-1640 medium (Gibco, Thermo Fisher, USA) supplemented with 10\% fetal

140 bovine serum (FBS) (Gibco, Thermo Fisher, USA), 100 U/ml recombinant human GM-CSF

141 (Peprotech, USA), $50 \mathrm{U} / \mathrm{ml}$ recombinant human IL-4 (Peprotech, USA), $100 \mathrm{U} / \mathrm{mL}$ penicillin,

142 and $100 \mu \mathrm{g} / \mathrm{mL}$ streptomycin for 5-6 days [22-24]. This cultivation method enhanced the

143 differentiation of monocytes into immature MDCs. The CD14- cells remaining after CD14 ${ }^{+}$

144 isolation were cultured in RPMI-1640 supplemented with 5\% FBS, 5\% autologous serum,

145 recombinant human IL-2 $(20 \mathrm{IU} / \mathrm{mL})$ (Peprotech, USA), $100 \mathrm{U} / \mathrm{mL}$ penicillin, and $100 \mu \mathrm{g} / \mathrm{mL}$

146 streptomycin for T-lymphocyte proliferation [24].

147 HPV16 E2 and p16INK4a proteins stimulate immature MDCs

148 The immature MDCs were seeded into 96-well plates and stimulated to become mature

149 MDCs by using HPV16 E2 or p16INK4a at various concentrations; 0, 50, 100, 150, 250, and 500

$150 \mathrm{ng} / \mathrm{mL}$ (added on day 5 and incubated for 48 hours). The stimulated MDCs were harvested,

151 washed and stained with FITC-HLA-DR, PE-CD80, APC-CD86 and PE-Cy7-CD83-tagged

152 monoclonal antibodies (BD Pharmingen, USA) and analyzed using flow cytometry (FACScanto

153 II, BD Biosciences, USA) [24]. 
154 Evaluation the role of MAPK pathways on maturation and

155 activation of MDCs

156 The role of MAPK pathways in the maturation of MDCs was determined by adding three

157 specific kinase inhibitors into immature MDCs at day 5. The specific kinase inhibitors were p38

158 MAPK inhibitor (SB203580, $50 \mu \mathrm{M}$ ), ERK inhibitor (PD98059, $50 \mu \mathrm{M}$ ), and JNK inhibitor

159 (SP600125, $20 \mu \mathrm{M})$. Two hours after addition of these inhibitors, HPV16 E2 and/or p16INK4a

160 were added and culture was continued for a further $48 \mathrm{hr}$. The cells were collected and examined

161 for CD83 expression by flow cytometry. The secretion of IL-12 and IL-1 $\beta$ was determined by

162 ELISA (Peprotech, USA) [24].

163 Specific protein-pulsed MDCs stimulate autologous T-lymphocyte

164 proliferation and IFN- $\gamma$ secretion

Immature MDCs were seeded into 96-well U-bottom plates and cultured in RPMI-1640 containing $10 \% \mathrm{FBS}, 100 \mathrm{U} / \mathrm{ml}$ rhGM-CSF, $50 \mathrm{U} / \mathrm{ml}$ rhIL-4, $100 \mathrm{U} / \mathrm{mL}$ penicillin, and 100

$167 \mu \mathrm{g} / \mathrm{mL}$ streptomycin. The immature MDCs were further stimulated with HPV16 E2, p16INK4a, 168 or HPV16 E2/p16INK4a at the determined optimal concentration for $24 \mathrm{hr}$. The protein-pulsed

169 MDCs were washed and co-cultured with autologous T lymphocytes in the ratio of protein170 pulsed MDCs:T cells at 1:1, 1:5, and 1:10. The supernatants were harvested after $24 \mathrm{hr}$ of co-

171 culture for determination of IFN- $\gamma$ secretion by ELISA. The cells were harvested for staining

172 with FITC-CD3, APC-CD4, and PerCP-Cy5.5-CD8-tagged monoclonal antibodies (BD

173 Pharmingen, USA) and intracellular IFN- $\gamma$ monoclonal antibodies (BD Pharmingen, USA) and

174 detected using flow cytometry [24]. 
175 Evaluation of HLA blockade on stimulation of T lymphocytes by

176 protein-pulsed MDCs

177 Immature MDCs were seeded into 96-well U-bottom plates and cultured in RPMI-1640

178 containing 10\% FBS, $100 \mathrm{U} / \mathrm{ml} \mathrm{rhGM-CSF,} 50 \mathrm{U} / \mathrm{ml} \mathrm{rhIL}-4,100 \mathrm{U} / \mathrm{mL}$ penicillin, and 100

$179 \mu \mathrm{g} / \mathrm{mL}$ streptomycin. The immature MDCs were further stimulated with HPV16 E2, p16INK4a,

180 or HPV16 E2/p16INK4a at the determined optimal concentration for $24 \mathrm{hr}$. Then, protein-pulsed

181 MDCs were washed and blockade antibodies added. These were mouse anti-human HLA-ABC

182 monoclonal antibody (eBioscience, USA) and mouse anti-human HLA-DR, DP, DQ monoclonal

183 antibodies (BDPharmingen, USA) for $2 \mathrm{hr}$ [25]. The protein-pulsed MDCs were washed and co-

184 cultured with autologous T lymphocytes in the ratio of protein-pulsed MDCs:T cells at 1:1, 1:5,

185 and 1:10. The supernatants were harvested after $24 \mathrm{hr}$ of co-culture for determination of IFN- $\gamma$

186 secretion by ELISA. The cells were harvested for staining with FITC-CD3, APC-CD4, and

187 PerCP-Cy5.5-CD8-tagged monoclonal antibodies (BD Pharmingen, USA) and intracellular IFN-

$188 \gamma$ monoclonal antibodies (BD Pharmingen, USA) and detected using flow cytometry [24, 25$].$

\section{Statistical analysis}

Experiments were performed independently three times. The data were analyzed using analysis of variance (ANOVA) and differences among the experimental groups tested using

192 Tukey's multiple-comparison test implemented in Prism version 5. The results are shown as the 193 mean and standard deviation (SD). The symbols * and \# indicate statistical significance, at $\mathrm{p}<$ 1940.05 , in comparisons with controls or between groups, respectively.

195

196 Results 
197 Frequency of common HLA class I and II alleles in the Thai

population and prediction of the immunogenic epitopes of HPV16

Online database information about common HLA class I and class II alleles in Thailand

201

202

203

was based on data from 16,807 people. The three most common HLA class I alleles were HLA$A * 02$, HLA-A*11, and HLA-A*24 with frequencies of $29.2,27.7$, and $17.3 \%$, respectively. The three most common HLA class II alleles were HLA-DRB1*15, HLA-DRB1*12, and HLADRB $1 * 04$ with frequencies of $17.5,16.9$, and $14.4 \%$, respectively (Table 1 ).

The prediction of HLA class I and class II epitopes for HPV16 E2 and p16INK4a proteins was performed using two databases, the 9-meric amino-acid residues and 15-meric amino-acid residues were predicted for HLA class I and class II alleles, respectively. The HPV16 E2 protein (365 amino-acid residues) has immunogenic epitopes for both types of HLA. Fig 1A shows common immunogenic epitopes of HPV16 E2 protein for HLA class I alleles including HLA-A*02:01, HLA-A*11:01, HLA-A*24:02, HLA-B*15:01, and HLA-B*40:01, and for HLA class II alleles including

HLA-DRBI*04:01 and HLA-DRBI*15:01. Similarly, the p16INK4a protein (156 amino-acid residues) also presents immunogenic epitopes for both types of HLA including HLA-A*02:01, HLA-A*11:01, HLA-A*24:02, HLA-B*15:01, HLA-B*40:01, HLA-DRBI*04:01, and HLADRBI*15:01 (Fig 1B). This suggests that these two proteins can be presented by antigenpresenting cells via HLA class I and class II molecules.

\section{Production of HPV16 E2 and p16INK4a protein in Escherichia coli}

\section{BL21}



twice. Identities of the proteins were confirmed by western blot using specific antibodies for

221 polyhistidine and HPV16 E2, respectively. We found the purified p16INK4a protein with a

222 polyhistidine tag was of the expected size, $18 \mathrm{kDa}$ (Fig 1C). The purified HPV16 E2-

223 polyhistidine tagged protein was $43 \mathrm{kDa}$ (Fig 1D). Therefore, these proteins were further used

224 for stimulating of MDCs and T lymphocytes.

225 HPV16 E2 and p16INK4a proteins induced phenotypic maturation

226 of MDCs

227

228

229

230

231

232

233

234

235

236

237

238

239

240

We determined the optimum concentrations of HPV16 E2 and p16INK4a proteins for stimulating the maturation of MDCs. Evaluation of the expression level of CD83, which is a marker of mature DCs, was done after stimulating CD14+ monocytes with HPV16 E2 and/or p16INK4a at various concentrations; 0, 50 100, 150, 250 and $500 \mathrm{ng} / \mathrm{mL}$ (treated on day 5 and cultured for 48 hours). We observed that CD14+ monocytes cultured with rhGM-CSF and rhIL-4 can be induced to develop to immature monocyte-derived DC (Fig 2B) when compared to negative control (CD14+ monocytes without rhGM-CSF and rhIL-4) (Fig 2A). The immature dendritic cells were stimulated with HPV16 E2 and p16INK4a proteins resulting in their differentiation into mature dendritic cells with more cytoplasmic protrusions (Fig 2C and 2D). However, their phenotypic were not significantly observed.

Both the percentage of positive cells and mean fluorescence intensity (MFI) of CD83 ${ }^{+}$ MDCs increased in a dose-dependent manner after stimulation with HPV16 E2 protein to peak at a concentration of $250 \mathrm{ng} / \mathrm{mL}$ (Figs $2 \mathrm{C}$ and 2D). For p16INK4a, percentage of positive cells and MFI of $\mathrm{CD} 83^{+} \mathrm{MDCs}$ peaked at $150 \mathrm{ng} / \mathrm{mL}$ (Figs 2E and 2F). Therefore, the optimum 
241 concentration of HPV16 E2 and p16INK4a proteins for further experiments were $250 \mathrm{ng} / \mathrm{mL}$ and

$242150 \mathrm{ng} / \mathrm{mL}$, respectively (Figs 2I and 2J).

243 HPV16 E2 and p16INK4a proteins stimulate the maturation and

244 activation of MDCs via MAPK pathway

To confirm whether HPV16 E2 and p16INK4a proteins stimulated immature MDCs via the MAPK pathway, immature MDCs were treated with p38 MAPK, ERK and JNK inhibitors in

separate experiments prior to stimulation with the determined optimum concentrations of HPV16

E2 and/or p16INK4a. We found that the inhibitors significantly decreased the percentage of

$\mathrm{CD} 3^{+}$MDCs in cultures stimulated by HPV16 E2 or p16INK4a proteins (Figs 3A and 3B).

Secretion levels of IL-1 $\beta$ did not significantly differ between all treatment groups (Fig 3C).

However, secretion of IL-12 was significantly lower in experiments where MAPK inhibitors were administered in conjunction with p16INK4a relative to p16INK4a alone (Fig 3D). In contrast, IL-12 levels were not suppressed when MAPK inhibitors were administered in conjunction with HPV16E2 or HPV16 E2 together with p16INK4a (Fig 3D). These findings suggest that the activation of MDCs by HPV16 E2 and/or p16INK4a proteins is via the MAPK 256 pathway.

MDCs pulsed with HPV16 E2 and p16INK4a stimulate CD4 ${ }^{+}$and

\section{$\mathrm{CD8}^{+} \mathrm{T}$ lymphocytes to produce IFN- $\gamma$}

To determine the capability of MDCs to process immunogenic epitopes, the populations of $\mathrm{CD}^{+}$and $\mathrm{CD}^{+} \mathrm{T}$ lymphocytes were examined. MDCs pulsed with HPV16 E2 and/or

261 p16INK4a were co-cultured with IL-2-cultured T lymphocytes in ratios of 1:1, 1:5, and 1:10.

262 Percentages of $\mathrm{CD}^{+}$and $\mathrm{CD}^{+} \mathrm{T}$ lymphocytes were not significantly different in all ratios (Figs 
$2634 \mathrm{~A}$ and 4B). Interestingly, the percentage of $\mathrm{CD}^{+} \mathrm{IFN}^{-} \gamma^{+} \mathrm{T}$ lymphocytes dramatically increased

264 ratio-wise after co-culture with MDCs pulsed with HPV16 E2 and/or p16INK4a (Fig 4C). The

265 percentage of $\mathrm{CD}^{+} \mathrm{IFN}-\gamma^{+} \mathrm{T}$ lymphocytes did not significantly differ between treatments at

266 ratios of $1: 5$ and $1: 10$. However, at the ratio of $1: 1$, the percentage of these lymphocytes was

267 significantly greater when MDCs were pulsed with HPV16 E2 or p16INK4a relative to the

268 combination of HPV16 E2 and p16INK4a (Fig 4D). This indicates that HPV16 E2 might exhibit

269 higher immunogenicity than the combination of HPV16 E2 and p16INK4a. The activation of

270 these proteins can be triggered via $\mathrm{CD} 4^{+}$or $\mathrm{CD} 8^{+}$lymphocytes. We further confirmed the

271 secretion of IFN- $\gamma$ using ELISA. Production of IFN- $\gamma$ was higher in co-cultures where MDCs

272 had been pulsed with HPV16 E2 rather than p16INK4a, and varied according to the ratio. The

273 combination of HPV16 E2 and p16INK4a significantly increased the production of IFN- $\gamma$ at

274 ratios of 1:5 and 1:10, while HPV16 E2 alone strongly induces the production of IFN- $\gamma$ in a

275 ratio-dependent manner (Fig 4E). This suggests that the activation of T lymphocytes by HPV16

276 E2 and p16INK4a for IFN- $\gamma$ production might be processed by $\mathrm{CD}^{+}$and $\mathrm{CD}^{+} \mathrm{T}$ lymphocytes.

$277 \mathrm{CD4}^{+}$and $\mathrm{CD8}^{+} \mathbf{T}$ lymphocytes co-response to combination of

278 HPV16 E2 and p16INK4a pulsed MDCs

To determine the effectiveness of HPV16 E2 and/or p16INK4a in stimulation of CD4 ${ }^{+}$or

$\mathrm{CD}^{+} \mathrm{T}$ lymphocytes, HLA blockade antibodies were specifically applied in co-culture

281

conditions at a ratio of 1:5. We found inhibition of IFN- $\gamma$ production in both HLA class I and II

282 blockade in co-culture with MDCs pulsed with a combination of HPV16 E2 and p16INK4a (Fig

283 4F). This effect was not apparent when the MDCs were pulsed with either HPV16 E2 alone or

284 p16INK4a alone (Fig 4F). Suggesting that the stimulation with combination of HPV16 E2 and

285 p16INK4a clearly enhances response of both $\mathrm{CD}^{+}$and $\mathrm{CD}^{+} \mathrm{T}$ lymphocytes. 


\section{Discussion}

288 Administration of protein subunits is a safe and effective strategy for HPV therapy by

289 stimulating immune responses [18]. The purpose of vaccine therapy against tumor or viral

290 infection is to stimulate T lymphocytes and differentiation of non-protective cells into functional

291 CTLs. The stimulation of T lymphocytes through dendritic cells, professional APCs, is an

292 efficient method [5]. Presentation of antigens by APCs to T lymphocytes occurs through the

293 HLA molecule: the HLA class II-bound peptide antigen is presented to CD4 ${ }^{+} \mathrm{T}$ lymphocytes

294 whereas the HLA class I-bound peptide antigen is presented to $\mathrm{CD} 8^{+} \mathrm{T}$ lymphocytes [7]. The

295 HPV16 E7 protein is a well-known antigen but has relatively low CTL epitopes which can only

296 be presented in association with HLA-A*33:03, an HLA class I allele [26]. The HPV16 E6

297 protein has a variety of epitopes that, in Chinese adolescents, can be presented in association

298 with HLA class II molecules such as HLA-DRB1 and HLA-DQB1 [27]. A number of HLA

299 alleles of both classes are common in Thailand (Table 1) and both HPV16 E2 and p16INK4a

300 proteins exhibit multiple epitopes that can be recognized by these alleles (Figs 1A and 1B).

301 HPV16 E2 and p16INK4a proteins are strong targets for stimulation of T lymphocytes via

302 dendritic cells.

303 The protein subunit was prepared using a popular bacterial system, Escherichia coli

304 BL21. This bacterial system capable provides the protein expression by regulating via T7

305 promoters which also used to produce the expression of HPV16 L1 [28] and HPV E7 [29].

306 Western blot indicated the size of our HPV16 E2-polyhistidine tagged protein to be $43 \mathrm{kDa}$ (Fig

307 1C) a size comparable to that reported previously for HPV16 E2-GFP (62 kD, but including the 
308 GFP of about $27 \mathrm{kDa}$ [ [30]. The size of our p16INK4a-polyhistidine tagged protein was $18 \mathrm{kDa}$

309 (Fig 1D), consistent with other reports.

310 The stimulation of dendritic cells by MtHSP70-FPR1 fusion protein, or Human

311 Immunodeficiency Virus (HIV)-1, can induce maturation of these by increasing the expression

312 of CD83, a marker for mature dendritic cells, and secretion of IL-1 $\beta$ and IL-12 [24, 31]. We

313 found that the HPV16 E2 and p16INK4a proteins also increase the expression of CD83 in MDCs

314 in a dose-dependent manner and induce cytoplasmic protrusions (Fig 2). Mature dendritic cells

315 play an important role as APCs to stimulate the differentiation of naïve T lymphocytes into

316 functional CTLs. However, the results of other MDCs maturation markers, including CD80,

317 CD86, and HLA-DR that were not significantly up-regulated in the experiment

318 (https://figshare.com/articles/HPV16E2 and p16INK4A project/1149351) as well as other

319 costimulating molecule are required for T cells response so these might be changed by the HPV

320 protein treatment of DCs. The maturation of dendritic cells also increases their secretion of IL-

$3211 \beta$ and IL-12, which are important in initiating T-lymphocyte responses and enhancing the

322 immune response. IL-12 stimulates the production of IFN- $\gamma$ by T lymphocytes whereas IL-1 $\beta$

323 can stimulate the growth of MDCs [24]. The MAPK-ERK signaling pathway controls the

324 survival of dendritic cells which can be stimulated by lipopolysaccharide (LPS) [32]. We found

325 that HPV16 E2 and p16INK4a proteins stimulate the secretion of IL-1 $\beta$ and IL-12 while the

326 partially suppression was found only in p16INK4A stimulation of IL-12 secretion by MAPK

327 inhibitors (Figs 3C and 3D). Interestingly, the MAPK inhibitors significantly suppress the

328 expression of CD83 in dendritic cells pulsed with HPV16 E2 or p16INK4a (Figs 3A and 3B).

329 These results suggest that the subunit proteins, HPV16 E2 and p16INK4a, individually or in

330 combination, stimulate the maturation of MDCs thus enhancing their APC properties. 
332 other approaches, CTLs can be stimulated by tumor-specific antigens or tumor-associated

333 antigens. Tumor-specific antigens in the case of HPV infection include the non-structural

334 proteins HPV16 E7 and HPV18 E7, which can stimulate specific T lymphocytes via APCs [33].

335 The structural L1 protein of HPV16 and HPV18 has been used as prophylactic vaccine against

336 HPV in combination with adjuvant system 04 (AS04) and also stimulates the maturation of

337 dendritic cells, secretion of pro-inflammatory cytokines and stimulation of cytotoxic activity

338 against HPV-infected tumors [34]. There have also been reports about the use of a combination

339 of non-structural HPV16 E7 protein and PD-L1 blockade, an immune blockade, which exhibited

340 highly effective stimulation of dendritic cells in vivo and an effective CTL response [35]. A

341 modified vaccinia virus, Ankara virus encoding bovine papillomavirus E2 (MVA-E2), enhances

342 the elimination of CIN lesions in the cervix [36]. The MtHSP70-FPR1 fusion protein, a tumor-

343 associated antigen has recently been reported to stimulate dendritic cells through the p38 MAPK

344 signaling pathway and to promote the specific responses of CTLs to cervical cancer cells [24].

345 Moreover, a combination of tumor-specific antigens and tumor-associated antigens may also

346 stimulate immune response. An example is the DNA encoding HPV-16 E7/HSP70 fusion

347 protein, which can stimulate the specific antitumor responses in mice [37]. The fusion protein

348 HPV-16 E6/E7 and Fms-like tyrosine kinase-3 ligand also stimulates the response of CD8 ${ }^{+} \mathrm{T}$

349 cells specific to E6 and E7 [18]. However, a strategy to develop a therapeutic vaccine against

350 HPV infection is not well developed.

351 The tumor-specific antigen, HPV E2, is an early protein that controls the expression of

352 E6 and E7 oncoproteins and is more immunogenic than either of these oncoproteins [38]. The

353 tumor-associated antigen, human p16INK4a, is a protein that acts as a tumor suppressor and is 
354 over-expressed in HPV infection [39]. Therefore, we considered HPV16 E2 and p16INK4a to be

355 important and interesting target proteins to stimulate the immune system of patients infected with

356 HPV. In this study, MDCs pulsed with HPV16 E2 and/or p16INK4a were able to stimulate

357 autologous $\mathrm{T}$ lymphocytes to proliferate and to secrete IFN- $\gamma$. The IFN- $\gamma$ is produced by $\mathrm{CD} 8^{+} \mathrm{T}$

358 lymphocytes that eliminate infected cells and $\mathrm{CD}^{+} \mathrm{T}$ lymphocytes that promote cell responses

359 through the presentation of HLA class I and II molecules [5, 7]. Particularly, the combination of

360 HPV16 E2 and p16INK4a proteins can promote greater T lymphocyte responses either protein

361 alone, which obviously stimulates via HLA class I and II (Figs 4E and 4F). The optimum

362 concentrations of the two proteins in combination, as used in this study to activate MDCs, were

$363250 \mathrm{ng} / \mathrm{ml}$ for HPV16 E2 and $150 \mathrm{ng} / \mathrm{ml}$ for p16INK4a. Combined subunit vaccines generally

364 use different concentrations of each antigen to elicit effective immune responses. An example is

365 the combined protein vaccine for diphtheria-tetanus-pertussis [40, 41]. Our study might provide a

366 strategy for development of HPV infection treatment using the optimum concentrations of

367 HPV16 E2 and p16INK4a proteins for stimulation of T lymphocytes.

368

369 Conclusions

In this study, we have evaluated immune-cell responses to HPV16 E2 and p16INK4a

371 proteins in blood from healthy volunteers. HPV E2 is a tumor-specific antigen and human

372 p16INK4a is a tumor-associated antigen that can stimulate MDCs cells through MAPK pathways

373 and increase the autologous T-lymphocyte response. The combination of HPV16 E2 and

374 p16INK4a proteins increases specific responses in both $\mathrm{CD}^{+}$and $\mathrm{CD}^{+} \mathrm{T}$ lymphocytes. Both

375 proteins can stimulate cell proliferation and IFN- $\gamma$ secretion by $\mathrm{CD} 8^{+} \mathrm{T}$ lymphocytes (that

376 eliminate infected cells) and $\mathrm{CD}^{+} \mathrm{T}$ lymphocytes (that promote cell responses) through the 
377 presentation of HLA class I and II molecules, respectively. We determined that the optimum

378 concentration of the proteins in combination was $250 \mathrm{ng} / \mathrm{ml}$ of HPV16 E2 and $150 \mathrm{ng} / \mathrm{ml}$ of

379 p16INK4a. This study provides strategies and optimal concentrations for developing therapies to

380 treat HPV infections using a combination of HPV16 E2 and p16INK4a proteins for stimulation

381 of T lymphocytes.

382

383 Acknowledgements

384 We sincerely thank research team members of Mahasarakham University and Khon Kean

385 University for helpful discussions. The authors gratefully acknowledge the financial support by

386 Khon Kean University (grant numbers 61004603 and 620008005) and scholarships under the

387 Post-doctoral Program from Research Affairs and Graduate School, Khon Kaen University

388 (grant no.58222 and PD2562-12). The funders had no role in study design, data collection and

389 analysis, decision to publish, or preparation of the manuscript. We would like to acknowledge

390 Prof. David Blair, for editing the MS via Publication Clinic KKU, Thailand.

391

392 Conflict of interest statement

393 The authors declare no conflict of interest for this study.

395 References

396 1. Shrestha AD, Neupane D, Vedsted P, Kallestrup P (2018) Cervical cancer prevalence,

397 incidence and mortality in low and middle income countries: A systematic review. Asian

$398 \quad$ Pacific J Cancer Prev 19:319-324 
399 2. De Martel C, Ferlay J, Franceschi S, Vignat J, Bray F, Forman D, Plummer M (2012)

$400 \quad$ Global burden of cancers attributable to infections in 2008: A review and synthetic

$401 \quad$ analysis. Lancet Oncol 13:607-615

402 3. Langsfeld E, Laimins LA (2016) Human Papillomaviruses: Research Priorities for the $403 \quad$ Next Decade. Trends in Cancer 2:234-240

404 4. Wieking BG, Vermeer DW, Spanos WC, Lee KM, Vermeer P, Lee WT, Xu Y, Gabitzsch

405 ES, Balcaitis S, Balint JP Jr, Jones FR, Lee JH (2012) A non-oncogenic HPV 16 E6/E7

406 vaccine enhances treatment of HPV expressing tumors. Cancer Gene Ther 19:667-674

407 5. Palucka K, Banchereau J (2013) Dendritic cell-based cancer therapeutic vaccines

$408 \quad$ Karolina. Immunity 39:38-48

409 6. Farkona S, Diamandis EP, Blasutig IM (2016) Cancer immunotherapy: The beginning of

410 the end of cancer? BMC Med 14:1-18

411 7. Yatim KM, Lakkis FG (2015) A brief journey through the immune system. Clin J Am Soc

$412 \quad$ Nephrol 10:1274-1281

413 8. Rosales R, Rosales C (2014) Immune therapy for human papillomaviruses-related cancers.

$414 \quad$ World J Clin Oncol 5:1002-1019

415 9. Stanley MA (2006) Human papillomavirus vaccines. Rev Med Virol 16:139-149

416 10. Arany I, Goel A, Tyring S k. (1995) Interferon response depends on viral transcription in

417 human papillomavirus-containing lesions. Anticancer Res 15:2865-2869

418 11. Ashrafi GH, Haghshenas MR, Marchetti B, O'Brien PM, Campo MS (2005) E5 protein of

419 human papillomavirus type 16 selectively downregulates surface HLA class I. Int J

$420 \quad$ Cancer 113:276-283

421 12. Ruas M, Peters G (1998) The p16INK4a/CDKN2A tumor suppressor and its relatives. 
423 13. McLaughlin-Drubin ME, Park D, Munger K (2013) Tumor suppressor p16INK4A is necessary for survival of cervical carcinoma cell lines. Proc Natl Acad Sci U S A

425 110:16175-16180

426

14. Piersma SJ, Welters MJ, van der Hulst JM, Kloth JN, Kwappenberg KM, Trimbos BJ, Melief CJ, Hellebrekers BW, Fleuren GJ, Kenter GG, Offringa R, van der Burg SH (2008) Human papilloma virus specific T cells infiltrating cervical cancer and draining lymph nodes show remarkably frequent use of HLA-DQ and -DP as a restriction element. Int $\mathbf{J}$ Cancer 122:486-494

15. Servinsky MD, Terrell JL, Tsao CY, Wu HC, Quan DN, Zargar A, Allen PC, Byrd CM, Sund CJ, Bentley WE (2016) Directed assembly of a bacterial quorum. ISME J 10:158169

16. Inoue H, Nojima H, Okayama H (1990) High efficiency transformation of Escherichia coli with plasmids. Gene 96:23-28

17. Kruger NJ (1994) The Bradford method for protein quantitation. Methods Mol Biol 32:9-

18. Li J, Chen S, Ge J, Lu F, Ren S, Zhao Z, Pu X, Chen X, Sun J, Gu Y (2017) A novel therapeutic vaccine composed of a rearranged human papillomavirus type 16 E6/E7 fusion protein and Fms-like tyrosine kinase-3 ligand induces CD8+ T cell responses and antitumor effect. Vaccine 35:6459-6467

19. Nielsen M, Lund O, Buus S, Lundegaard C (2010) MHC Class II epitope predictive algorithms. Immunology 130:319-328

20. Nielsen M, Andreatta M (2016) NetMHCpan-3.0; improved prediction of binding to MHC 
445 class I molecules integrating information from multiple receptor and peptide length

446 datasets. Genome Med 8:1-9

447 21. Müller G, Kerkhoff C, Hankowitz J, Pataki M, Kovacs E, Lackner KJ, Schmitz G (1993)

448 Effects of purinergic agents on human mononuclear phagocytes are differentiation

449 dependent: Implications for atherogenesis. Arterioscler Thromb Vasc Biol 13:1317-1326

450 22. Murray PJ, Allen JE, Fisher EA, Lawrence T (2015) Macrophage ac1. Murray, P. J.,

451 Allen, J. E., Fisher, E. A. \& Lawrence, T. Macrophage activation and polarization

452 nomenclature and experimental guidelines. 41, 14-20

453 23. Steevels TAM, Meyaard L (2011) Immune inhibitory receptors: Essential regulators of 454 phagocyte function. Eur J Immunol 41:575-587

455 24. Xiao M, Feng Y, Cao G, Liu C, Zhang Z (2018) A novel MtHSP70-FPR1 fusion protein 456 enhances cytotoxic T lymphocyte responses to cervical cancer cells by activating human 457 monocyte-derived dendritic cells via the p38 MAPK signaling pathway. Biochem Biophys 458 Res Commun 503:2108-2116

459 25. Rahman M, Steuer J, Gillgren P, Hayderi A, Liu A, Frostegård J (2017) Induction of 460 dendritic cell-mediated activation of $\mathrm{T}$ cells from atherosclerotic plaques by human Heat 461 Shock protein 60. J Am Heart Assoc 6:1-15

462 26. Kim S, Chung HW, Kong HY, Lim JB (2017) Identification of novel immunogenic 463 human papillomavirus type $16 \mathrm{E} 7$-specific epitopes restricted to HLA-A*33;03 for 464 cervical cancer immunotherapy. Yonsei Med J 58:43-50

465 27. Hu Y, Wu JZ, Zhu H, Zhang SH, Zhu YY, Wu Y yao, Shuai CX (2017) Association of 466 HLA-DRB1, HLA-DQB1 Polymorphisms with HPV 16 E6 Variants among Young

467 Cervical Cancer Patients in China. J Cancer 8:2401-2409 
468 28. Bang HB, Lee YH, Lee YJ, Jeong KJ (2015) High-level production of human

469 papillomavirus (HPV) type 1611 in escherichia coli. J Microbiol Biotechnol 26:356-363

470 29. Viana DA, Santos DL, Leitão MCG, Ferreira LC, Neto BB, Filho JLL, Moreira KA,

471 Converti A, Porto ALF (2009) Screening of variables influencing the production of HPV

472 E7 oncoproteins by recombinant Escherichia coli. Biotechnology 8:62-69

473 30. Sunthamala N, Thierry F, Teissier S, Pientong C, Kongyingyoes B, Tangsiriwatthana T, 474 Sangkomkamhang U, Ekalaksananan T (2014) E2 proteins of high risk human papillomaviruses down-modulate STING and IFN- $\kappa$ transcription in keratinocytes. PLoS One. https://doi.org/10.1371/journal.pone.0091473

31. Wilflingseder D, Müllauer B, Schramek H, Banki Z, Pruenster M, Dierich MP, Stoiber H (2004) HIV-1-Induced Migration of Monocyte-Derived Dendritic Cells Is Associated with Differential Activation of MAPK Pathways. J Immunol 173:7497-7505

32. Rescigno M, Martino M, Sutherland CL, Gold MR, Ricciardi-Castagnoli P (1998)

Dendritic cell survival and maturation are regulated by different signaling pathways. J Exp

482 Med 188:2175-2180

483 33. Ferrara A, Nonn M, Sehr P, Schreckenherger C, Pawlita M, Dürst M, Schneider A, 484 Kaufmann AM (2003) Dendritic cell-based tumor vaccine for cervical cancer II: Results of a clinical pilot study in 15 individual patients. J Cancer Res Clin Oncol 129:521-530

34. Van den Bergh JM, Guerti K, Willemen Y, Lion E, Cools N, Goossens H, Vorsters A, Van Tendeloo VF, Anguille S, Van Damme P, Smits EL (2014) HPV vaccine stimulates cytotoxic activity of killer dendritic cells and natural killer cells against HPV-positive tumour cells. J Cell Mol Med 18:1372-1380 
491 E7 synthetic vaccine in combination with PD-L1 blockade elicits therapeutic antitumor

492 immunity in mice. Oncoimmunology 5:1-9

493 36. Rosales R, López-Contreras M, Rosales C, Magallanes-Molina JR, Gonzalez-Vergara R, 494 Arroyo-Cazarez JM, Ricardez-Arenas A, Del Follo-Valencia A, Padilla-Arriaga S, 495 Guerrero MV, Pirez MA, Arellano-Fiore C, Villarreal F (2014) Regression of human 496 papillomavirus intraepithelial lesions is induced by MVA E2 therapeutic vaccine. Hum 497 Gene Ther 25:1035-1049

37. Soleimanjahi H, Razavinikoo H, Fotouhi F, Ardebili A (2017) Antitumor response to a codon-optimized HPV-16 E7/HSP70 fusion antigen DNA vaccine. Iran J Immunol $14: 180-191$

38. Pérez-Plasencia C, Dueñas-Gonzalez A, Bustos-Martínez J (2008) Activación de la vía de 502 Wnt/beta catenina en el proceso de carcinogenesis cervical. Arch Med.

503 https://doi.org/10.1186/1755-7682-1-10

39. Lechner M, Chakravarthy AR, Walter V, Masterson L, Feber A, Jay A, Weinberger PM, McIndoe RA, Forde CT, Chester K, Kalavrezos N, O'Flynn P, Forster M, Jones TM, Vaz FM, Hayes DN, Fenton TR (2018) Frequent HPV-independent p16/INK4A overexpression in head and neck cancer. Oral Oncol 83:32-37

40. Centers for Disease Control and Prevention (2018) About Diphtheria, Tetanus, and 509 Pertussis Vaccines. www.cdc.gov/vaccines/vpd/dtap-tdap-td/hcp/about-vaccine.html. Accessed 18 Nov 2019

511 41. World Health Organization (2014) The Vaccines. https://www.who.int/vaccine_safety/initiative/tools/DTP_vaccine_rates_information_shee t.pdf. Accessed 18 Nov 2019 


\section{Figure Legends}

517 Figure 1. Mapping of immunogenic epitopes and protein sizes of p16INK4a and HPV16 E2.

518 Possible immunogenic epitopes of (A) HPV16 E2 and (B) p16INK4a were mapped using two

519 databases, SYFPEITHI and NetMHCpan version 4.0. The prediction was performed by using 9-

520 meric amino-acid residues for HLA class I epitope binding and 15-meric amino-acid residues for

521 HLA class II, respectively. The protein sizes of (C) p16INK4a and (D) HPV16 E2 were checked

522 by western blot.

523

524 Figure 2. Stimulation of immature MDCs by HPV16 E2 and p16INK4a proteins. (A)

525 Characteristics of CD14+ monocytes cultured in RPIM-1640 medium without GM-CSF and IL-

526 4. (B) Characteristics of CD14+ monocytes in RPIM-1640 medium with GM-CSF and IL-4

527 before stimulation. (C) Characteristics of mature MDCs treated with HPV16E2 at concentration

528 of $250 \mathrm{ng} / \mathrm{mL}$. (D) Characteristics of mature MDCs treated with p16INK4A at concentration of

$529150 \mathrm{ng} / \mathrm{mL}$. (E) Percentage and (F) Mean fluorescence intensity (MFI) of CD83 ${ }^{+}$MDCs

530 stimulated by HPV16 E2 protein at various concentrations. (G) Percentage and (H) MFI of

$531 \mathrm{CD}^{2} 3^{+}$MDCs stimulated by p16INK4a protein at various concentrations. (I) Percentage and (J)

532 Mean fluorescence intensity (MFI) of CD $83^{+}$MDCs stimulated by HPV16E2 and p16INK4A

533 proteins at best concentrations. The untreated group is immature MDCs without stimulation with

534 any proteins. The experiments were performed by using 5 healthy volunteers and repeated the

535 experiment three times. (*) p-value $<0.05$ compared to control. (\#) p-value $<0.05$ compared

536 between groups. 
538 Figure 3. Expression of CD83 and cytokine production by MDCs stimulated by HPV16 E2

539 and/or p16INK4a proteins. (A) The expression of CD83 stimulated by HPV16 E2 and (B)

540 p16INK4a after treatment with p38 MAPK inhibitor (SB203580), ERK inhibitor (PD98059), or

541 JNK (SP600125), examined using flow cytometry. (C) The production of IL-1 $\beta$ (pg/mL) and (D)

542 IL-12 after blocking of MDCs with SB203580, PD98059 or SP600125, then stimulated by

543 HPV16 E2 and/or p16INK4a proteins. The HPV16 E2 protein concentration was $250 \mathrm{ng} / \mathrm{mL}$ and

$544 \mathrm{p} 16 \mathrm{INK} 4 \mathrm{~A}$ protein concentration was $150 \mathrm{ng} / \mathrm{mL}$. The experiments were performed by using 5

545 healthy volunteers and repeated the experiment three times in each volunteer blood sample. $(*)$

546 p-value $<0.05$ compared to control. (\#) p-value $<0.05$ compared between groups.

548 Figure 4. MDCs pulsed with HPV16 E2 and/or p16INK4a stimulate $\mathrm{CD}^{+}$and $\mathrm{CD}^{+} \mathrm{T}$

549 lymphocytes. (A) The percentage of $\mathrm{CD}^{+} \mathrm{T}$ lymphocytes and (B) $\mathrm{CD} 8^{+} \mathrm{T}$ lymphocytes in co-

550 cultures with MDCs pulsed with HPV16 E2 and/or p16INK4a at various ratios. (C) The

551 percentage of IFN $-\gamma^{+} \mathrm{CD} 4^{+} \mathrm{T}$ lymphocytes and (D) IFN- $\gamma^{+} \mathrm{CD} 8^{+} \mathrm{T}$ lymphocytes in co-cultures

552 with MDCs pulsed with HPV16 E2 and/or p16INK4a at various ratios. (E) The concentration of

553 IFN- $\gamma(\mathrm{pg} / \mathrm{mL})$ after co-culture of T lymphocytes with MDCs pulsed with HPV16 E2 and/or

554 p16INK4a at various ratios. (F) The concentration of IFN- $\gamma(\mathrm{pg} / \mathrm{mL})$ after blockade with HLA

555 class I and II antibodies and co-culture of T lymphocytes and MDCs pulsed with HPV16 E2

556 and/or p16INK4a at a ratio of 1: 5. The HPV16 E2 protein concentration was $250 \mathrm{ng} / \mathrm{mL}$ and

$557 \mathrm{p} 16 \mathrm{INK} 4 \mathrm{~A}$ protein concentration was $150 \mathrm{ng} / \mathrm{mL}$. The experiments were performed by using 5

558 healthy volunteers and repeated the experiment three times in each volunteer blood sample. $(*)$

559 p-value $<0.05$ compared to control. (\#) p-value $<0.05$ compared between groups. 


\section{Table}

562 Table 1. The table showed \% frequency of HLA class I and II alleles that are commonly found 563 in the Thai population.

564 


\section{Table $\mathbf{1}$ (on next page)}

Table 1 . The table showed \% frequency of HLA class I and II alleles that are commonly found in the Thai population. 
1 Table 1. The frequency of common HLA class I and II alleles in Thai populations

\begin{tabular}{cccc}
\hline \multicolumn{2}{c}{ HLA class I } & \multicolumn{2}{c}{ HLA class II } \\
\hline Allele & \% Allele Frequency & Allele & \% Allele Frequency \\
\hline HLA-A $* 2$ & 29.2 & HLA-DRB1*04 & 14.4 \\
HLA-A 11 & 27.7 & HLA-DRB1*09 & 11.5 \\
HLA-A 24 & 17.3 & HLA-DRB1*12 & 16.9 \\
HLA-A $* 33$ & 13.8 & HLA-DRB1*15 & 17.5 \\
HLA-B*15 & 14.8 & & \\
HLA-B*40 & 13.4 & & \\
HLA-B*46 & 13.2 & & \\
\hline
\end{tabular}

2

3 


\section{Figure 1}

Figure 1. Mapping of immunogenic epitopes and protein sizes of p16INK4a and HPV16 E2.

Figure 1. Mapping of immunogenic epitopes and protein sizes of p16INK4a and HPV16 E2. Possible immunogenic epitopes of (A) HPV16 E2 and (B) p16INK4a were mapped using two databases, SYFPEITHI and NetMHCpan version 4.0. The prediction was performed by using 9meric amino-acid residues for HLA class I epitope binding and 15-meric amino-acid residues for HLA class II, respectively. The protein sizes of (C) p16INK4a and (D) HPV16 E2 were checked by western blot. 
A

HLA-A*11:01 HLA-A*02:01

METLCQRLNVCQDKILTHYENDSTDLRDHIDYWKHMRLECAIYYKAREMGIKHINHQVVPTLAVSKNKALQAIELQLTLETIYNS

HLA-A*24:02

HLA-DRBI*04:01 HLA-B*15:01

QYSNEKWTLQDVSLEVYLTAPTGCIKKHGYTVEVQFDGDICNTMHYTNWTHIYICEEASVTVVEGQVDYYGLYYVHEGIRTYFVQF

HLA-B*40:01

KDDAEKYSKNKVWEVHAGGQVILCPTSVFSSNEVSSPEIIRQHLANHSAATHTKAVALGTEETQTTIQRPRSEPDTGNPCHTTKLLHR

$\overbrace{\text { HLA-DRBI*04:01 }}^{\text {HLA-A*11:01 }}$

DSVDSAPILTAFNSSHKGRINCNSNTTPIVHLKGDANTLKCLRYRFKKHCKLYTAVSSTWHWTGHNVKHKSAIVTLTYDSEWQRDQFL HLA-DRBI*15:01

HLA-B*15:01

SQVKIPKTITVSTGFMSI

B

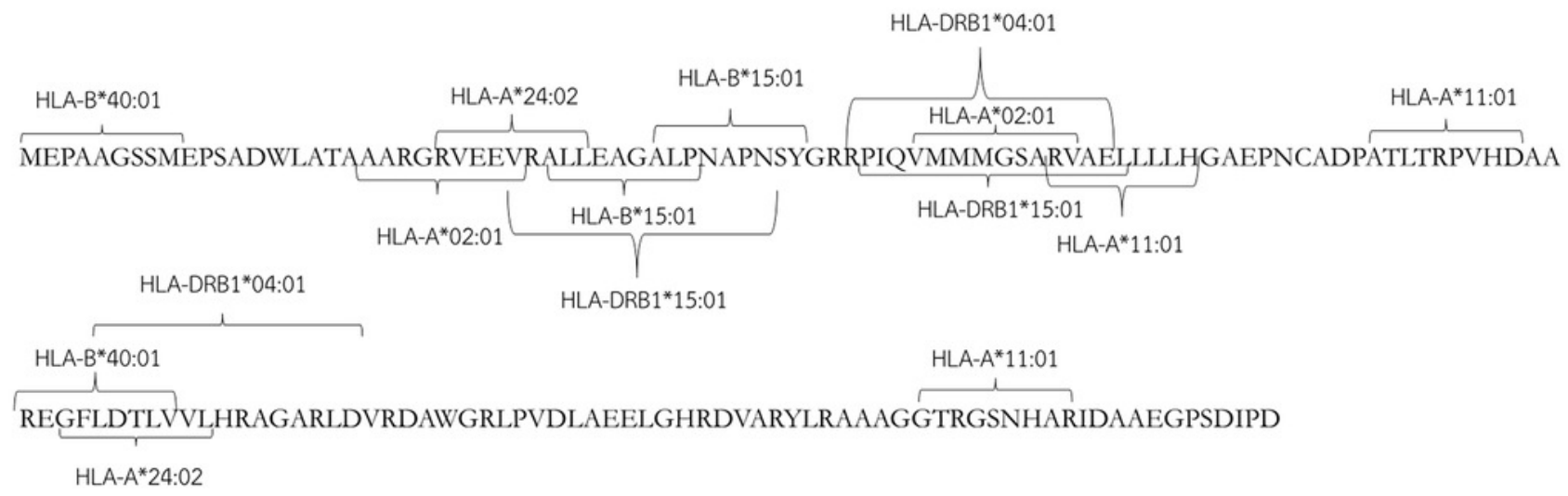

C

Elution

p16INK4a

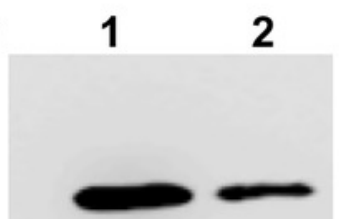

$18 \mathrm{kDa}$

D HPV16 E2

Elution 12 


\section{Figure 2}

Figure 2. Stimulation of immature MDCs by HPV16 E2 and p16INK4a proteins.

Figure 2. Stimulation of immature MDCs by HPV16 E2 and p16INK4a proteins. (A) Characteristics of CD14+ monocytes cultured in RPIM-1640 medium without GM-CSF and IL-4. (B) Characteristics of CD14+ monocytes in RPIM-1640 medium with GM-CSF and IL-4 before stimulation. (C) Characteristics of mature MDCs treated with HPV16E2 at concentration of $250 \mathrm{ng} / \mathrm{mL}$. (D) Characteristics of mature MDCs treated with p16INK4A at concentration of $150 \mathrm{ng} / \mathrm{mL}$. (E) Percentage and (F) Mean fluorescence intensity (MFI) of $\mathrm{CD} 3^{+}$MDCs stimulated by HPV16 E2 protein at various concentrations. (G) Percentage and (H) MFI of CD83 ${ }^{+}$MDCs stimulated by p16INK4a protein at various concentrations. (I) Percentage and (J) Mean fluorescence intensity (MFI) of CD83 ${ }^{+}$MDCs stimulated by HPV16E2 and p16INK4A proteins at best concentrations. The untreated group is immature MDCs without stimulation with any proteins. The experiments were performed by using 5 healthy volunteers and repeated the experiment three times. $(*)$ p-value $<0.05$ compared to control. (\#) p-value $<0.05$ compared between groups. 

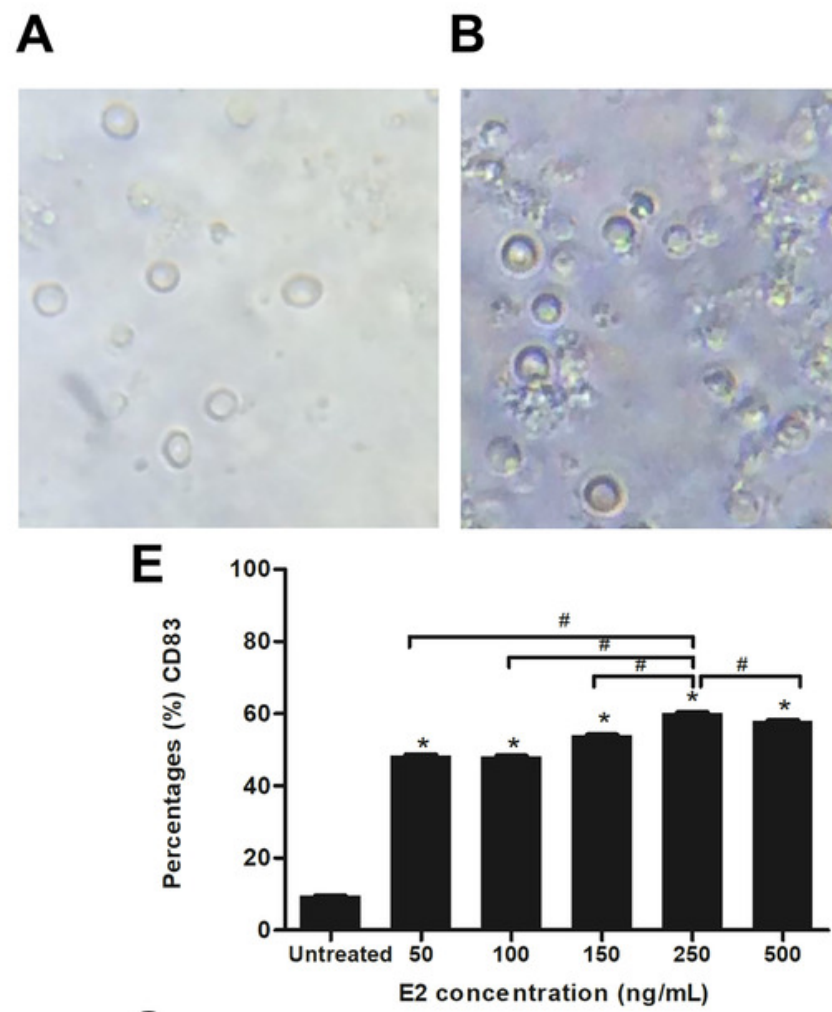

G

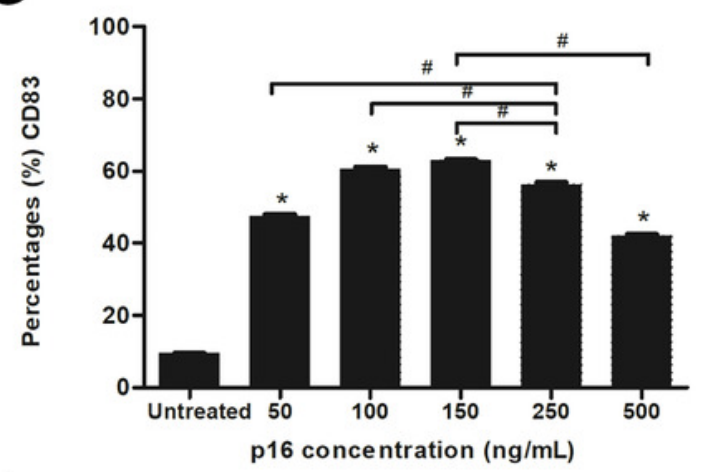

I

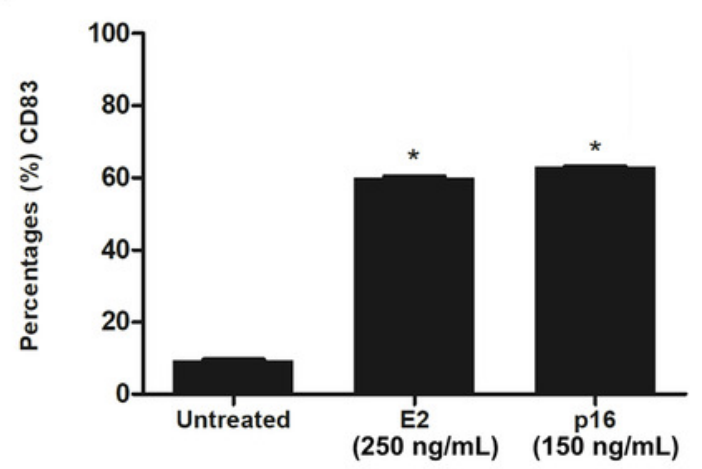

C
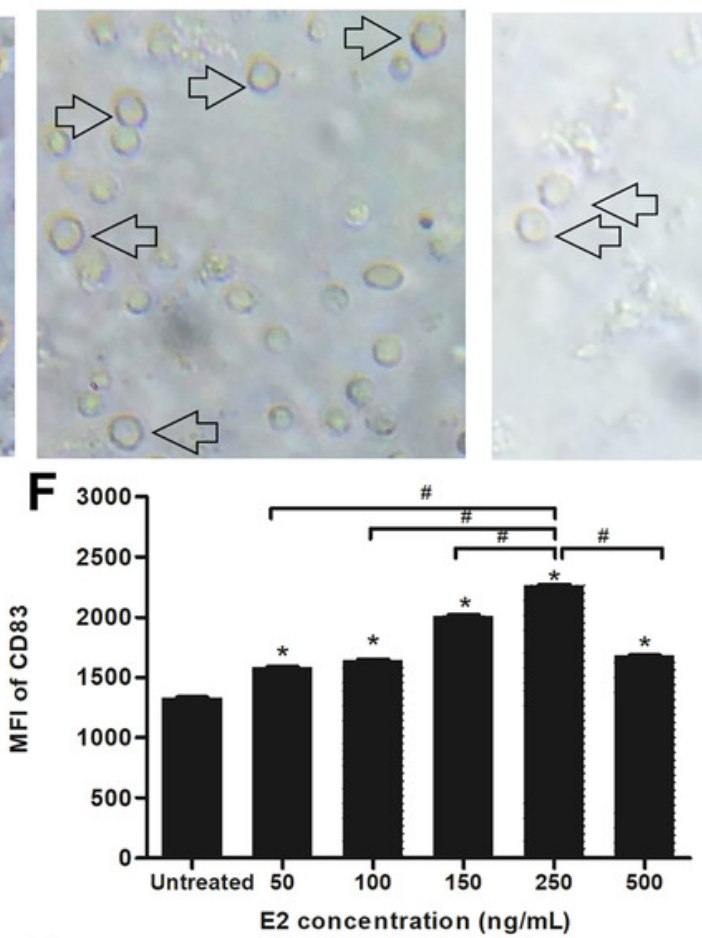

H

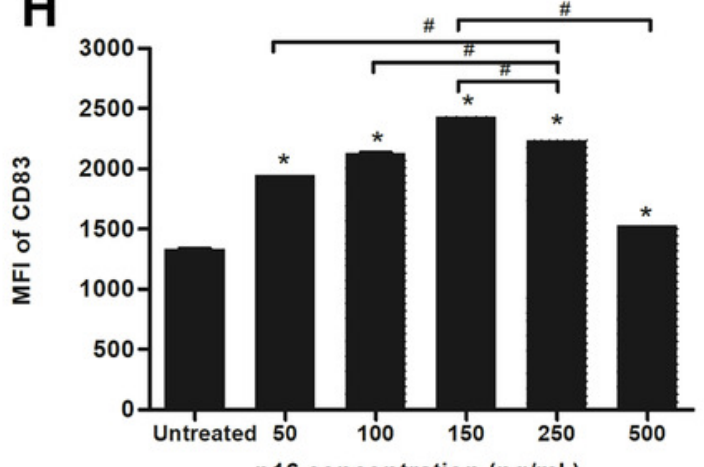

J

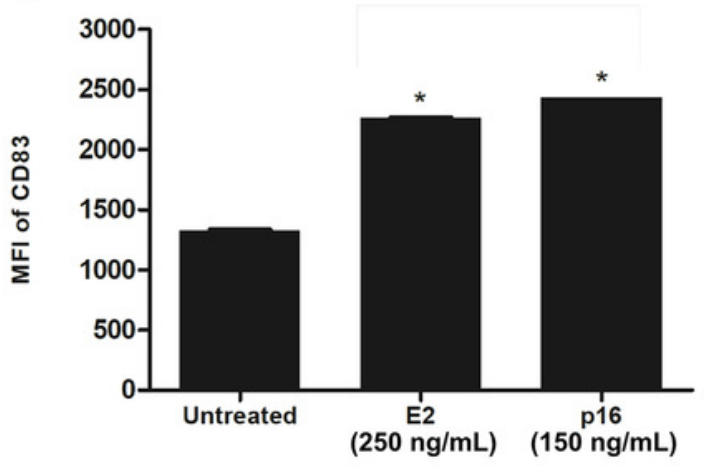




\section{Figure 3}

Figure 3. Expression of CD83 and cytokine production by MDCs stimulated by HPV16 E2 and/or p16INK4a proteins.

Figure 3. Expression of CD83 and cytokine production by MDCs stimulated by HPV16 E2 and/or p16INK4a proteins. (A) The expression of CD83 stimulated by HPV16 E2 and (B) p16INK4a after treatment with p38 MAPK inhibitor (SB203580), ERK inhibitor (PD98059), or JNK (SP600125), examined using flow cytometry. (C) The production of IL-1 $(\mathrm{pg} / \mathrm{mL})$ and (D) IL-12 after blocking of MDCs with SB203580, PD98059 or SP600125, then stimulated by HPV16 E2 and/or p16INK4a proteins. The HPV16 E2 protein concentration was $250 \mathrm{ng} / \mathrm{mL}$ and p16INK4A protein concentration was $150 \mathrm{ng} / \mathrm{mL}$. The experiments were performed by using 5 healthy volunteers and repeated the experiment three times in each volunteer blood sample. (*) p-value $<0.05$ compared to control. (\#) p-value $<0.05$ compared between groups. 
A

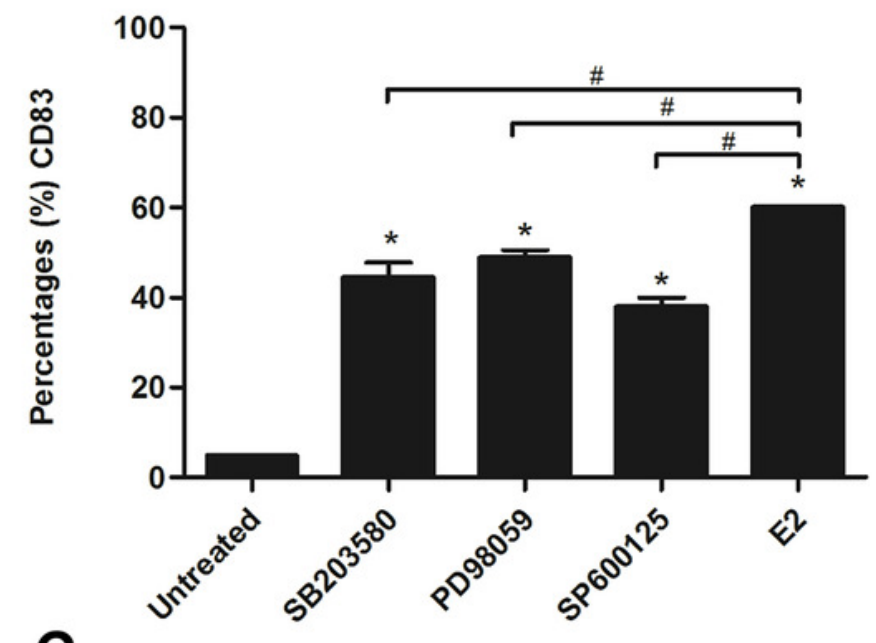

C

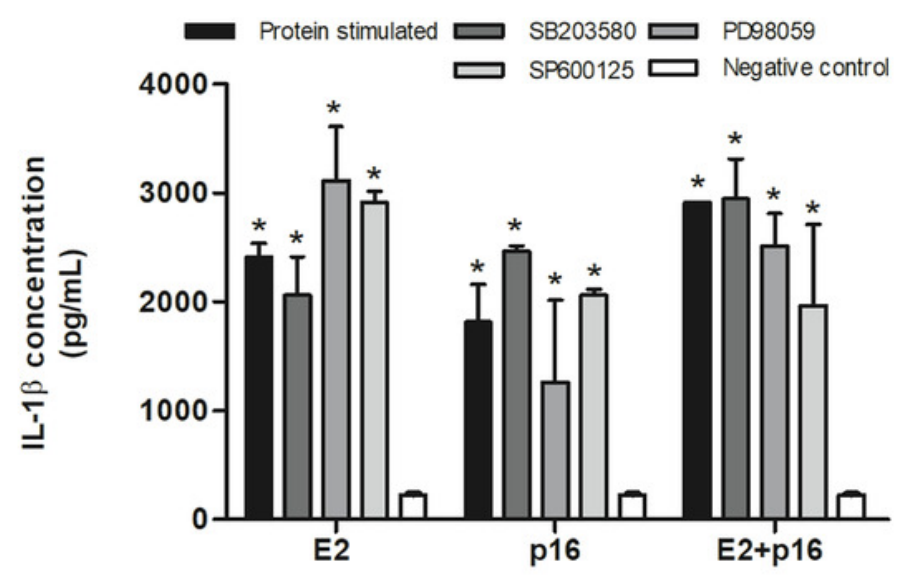

B

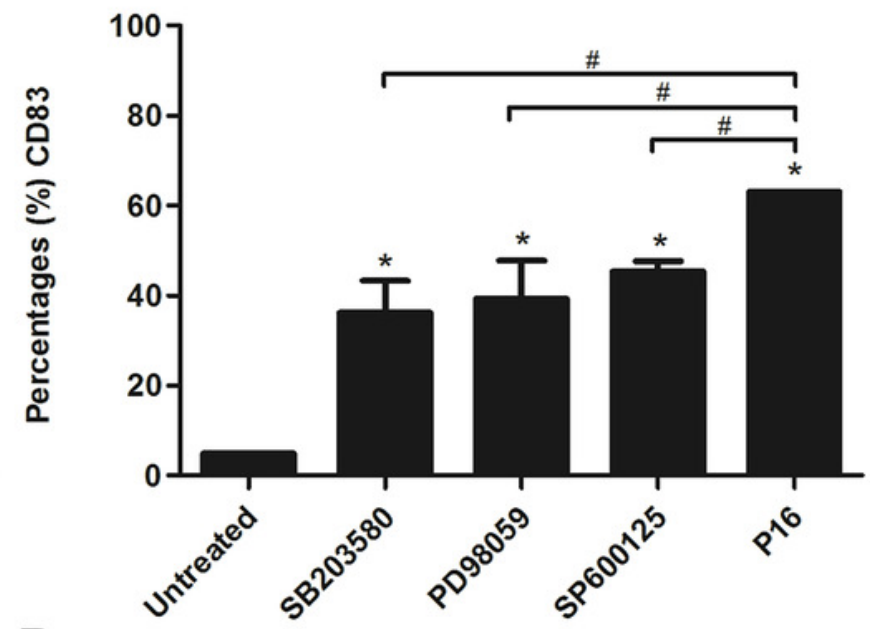

D

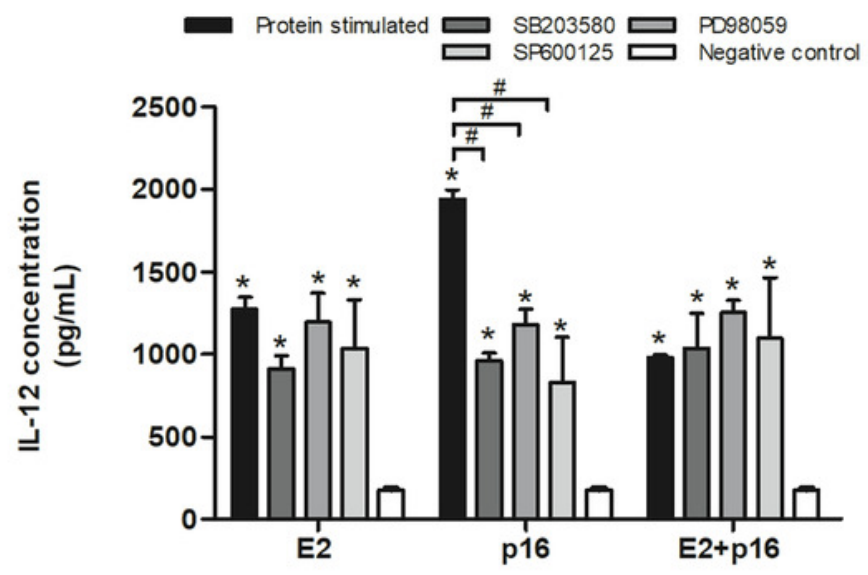




\section{Figure 4}

Figure 4. MDCs pulsed with HPV16 E2 and/or p16INK4a stimulate $\mathrm{CD} 4^{+}$and $\mathrm{CD} 8^{+} \mathrm{T}$ lymphocytes.

Figure 4. MDCs pulsed with HPV16 E2 and/or p16INK4a stimulate $C D 4^{+}$and $C D 8^{+} \mathrm{T}$ lymphocytes. (A) The percentage of $\mathrm{CD} 4^{+} \mathrm{T}$ lymphocytes and (B) $\mathrm{CD} 8^{+} \mathrm{T}$ lymphocytes in cocultures with MDCs pulsed with HPV16 E2 and/or p16INK4a at various ratios. (C) The percentage of IFN- $\gamma^{+} \mathrm{CD} 4^{+} \mathrm{T}$ lymphocytes and (D) IFN- $\gamma^{+} \mathrm{CD} 8^{+} \mathrm{T}$ lymphocytes in co-cultures with MDCs pulsed with HPV16 E2 and/or p16INK4a at various ratios. (E) The concentration of IFN- $\gamma(\mathrm{pg} / \mathrm{mL}$ ) after co-culture of T lymphocytes with MDCs pulsed with HPV16 E2 and/or p16INK4a at various ratios. (F) The concentration of IFN- $\gamma(\mathrm{pg} / \mathrm{mL})$ after blockade with HLA class I and II antibodies and co-culture of T lymphocytes and MDCs pulsed with HPV16 E2 and/or p16INK4a at a ratio of 1: 5. The HPV16 E2 protein concentration was $250 \mathrm{ng} / \mathrm{mL}$ and p16INK4A protein concentration was $150 \mathrm{ng} / \mathrm{mL}$. The experiments were performed by using 5 healthy volunteers and repeated the experiment three times in each volunteer blood sample. (*) p-value $<0.05$ compared to control. (\#) p-value $<0.05$ compared between groups. 


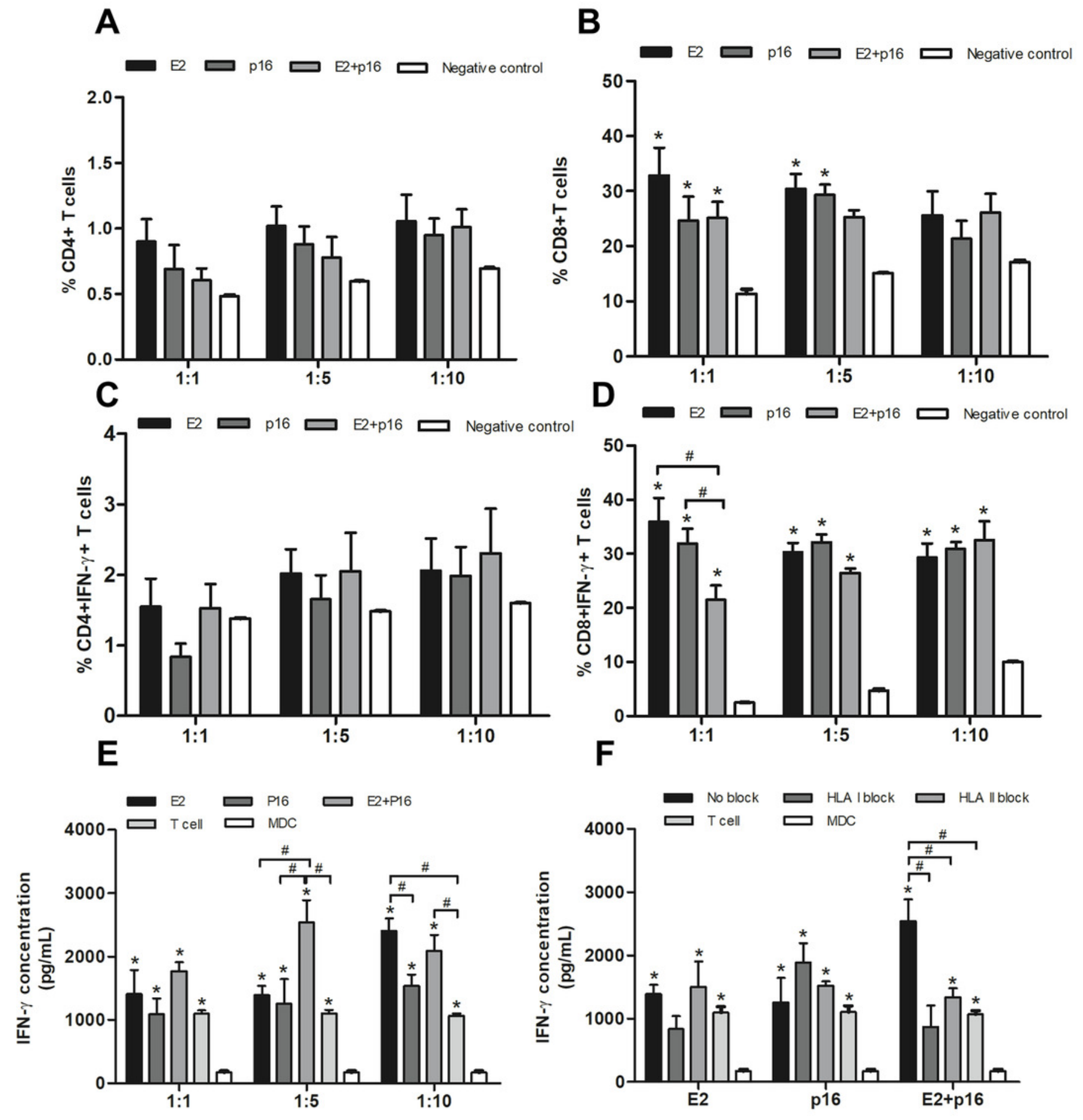

